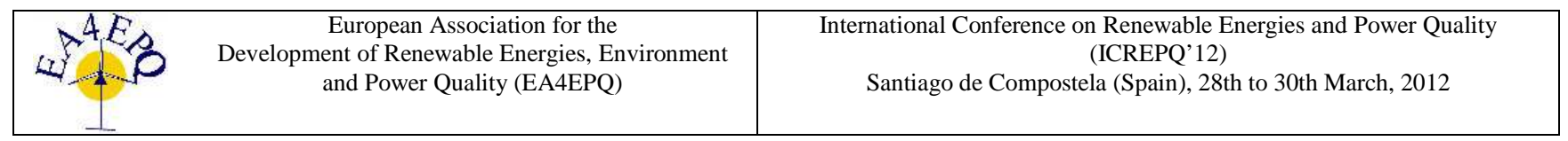

\title{
Temperature of Wood Char Particles Burning in a Fluidized Bed Reactor
}

\author{
N. Tomé, N. Rangel and C. Pinho \\ CEFT/DEMec, Faculdade de Engenharia, Universidade do Porto, Rua Dr. Roberto Frias, s/n, 4200-465 Porto (Portugal) \\ Phone/Fax number: +351 225081400 / +351 225081440, e-mail: ctp@fe.up.pt
}

\begin{abstract}
In the present work it was studied the fluidized bed combustion of char particles made with wood of Mozambican origin to find out the evolution of the particles temperature during the combustion process. Samples of wood species Afzelia quanzensis and Pterocarpus angolensis were carbonized at 850 ${ }^{\circ} \mathrm{C}$ in a nitrogen flow. Afterwards some of these char particles with sizes in the 9 to $13 \mathrm{~mm}$ range were burned in a bubbling fluidized bed, while at the same time their interior temperatures were measured. From the experiments, it was found that for these chars fragmentation was absent and that the measured temperatures with a thermocouple inserted into the particles was similar to the values that were obtained by means of an energy balance carried out at the surface of the particle.
\end{abstract}

\section{Key words}

Fluidized bed combustion, Particle temperature, Wood char

\section{Introduction}

Kinetic parameters concerning the combustion of batches of char particles in fluidized bed are usually presented in the form of an Arrhenius equation, but either for the determination of such correlation or for calculation or design purposes it is necessary to know the particle temperature. In a simplified approach it is commonly assumed that particles and bed are at the same temperature. The reactor is then considered as isothermal and particles composing the batch under combustion are at bed temperature. This assumption may lead to some errors in the calculations; Roscoe et al. [1] found out that for coke burning in a bed at $930{ }^{\circ} \mathrm{C}$, particles could be from 130 to $160{ }^{\circ} \mathrm{C}$ above the bed temperature. But although this is experimental evidence supported by visualization readings that realize the existence of brighter particles at the surface of the bed, it might be possible that these brighter particles are not fully representative of the majority of particles that remain burning deep inside the bed. Particles at the bed surface do not suffer the same quenching effects that act upon immersed particles and consequently burn under a different mechanism. The carbon at their surface reacts to $\mathrm{CO}_{2}$, whereas for those immersed in the bed the carbon only reacts to $\mathrm{CO}$; the combustion of $\mathrm{CO}$ is away from the particle surface, out of the boundary layer for oxygen diffusion.

There are some contradictions among the several authors that have been working on this matter. After a revision of experimental and analytical methods that have been used to find out the temperature of the burning particles done by Oka [2], the author concluded that it is still required more experimental research work to clarify this matter. As an example there is the work of Khraisha [3] where it is assumed that particles burn at bed temperature, while in the Komatina et al. [4] work it can be found that the type of char, the size of the batch and the concentration of $\mathrm{O}_{2}$ in the reactor, all influence the evolution of the temperature of the particles during combustion. Some authors refer that, either the particle temperature raise comparative to the bed temperature has not been properly considered, or it is usually adopted a temperature increment proportional to the initial size of the particle $\left(50{ }^{\circ} \mathrm{C}\right.$ for particles with an initial diameter below $1 \mathrm{~mm}$ and $150{ }^{\circ} \mathrm{C}$ for particles whose initial diameter is above 1 $\mathrm{mm})$.

As an alternative, either to simplistic approaches or to complicated experimental temperature measurements, as well as for design purposes, it is here proposed an analysis based on the energy balance of the surface of the burning char particle. The objective is to calculate the particle temperature by means of a semi-analytical method, and compare the obtained results with those experimentally measured.

\section{Theoretical Background}

The model to be used for the calculation of the particle temperature $T_{p}$ is based on the energy balance at the surface of such particle, and accounts for the heat of reaction as well as conduction and radiative heat exchanges between the particle and the surrounding bed, Fig. 1. Although it might seem awkward, it is assumed that the combustion reaction develops itself in steady state conditions, but this is a reasonable assumption because the calculation will be carried out for short time intervals when compared with the total particle burning time and so the heat transferred to the interior of the char 
particle $\dot{Q}_{s-i}$ is negligible. The terms $\dot{m}_{c} h_{c}, \dot{m}_{\mathrm{O} 2} h_{\mathrm{O} 2}$ and $\dot{m}_{\mathrm{CO}} h_{\mathrm{CO}}$ are, respectively, the energy fluxes associated to the carbon, oxygen and $\mathrm{CO} ; \dot{Q}_{s-b}$ and $\dot{Q}_{r a d}$ are the heats transferred to the surrounding bed by conduction and radiation, respectively. In radiative heat transfer it is assumed that the gas-phase layer involving the particle is a non-participating medium in the radiation and the view factor between the particle and the surrounding bed is unitary.

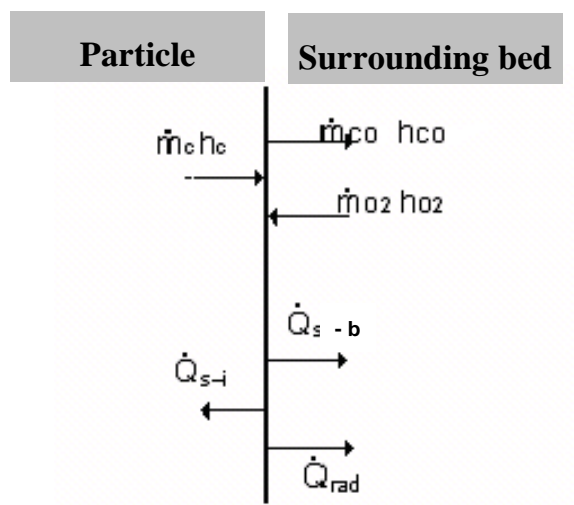

Fig. 1. Energy transfers at the particle surface assuming incomplete combustion at surface $\left(\mathrm{C}+1 / 2 \mathrm{O}_{2} \rightarrow \mathrm{CO}\right)$.

Therefore, the energy balance at particle surface becomes

$$
\dot{m}_{c} \Delta h+\dot{Q}_{s-b}+\dot{Q}_{r a d}=0
$$

where $\Delta h$ is the enthalpy of combustion for the reaction $\mathrm{C}+1 / 2 \mathrm{O}_{2} \rightarrow$ CO. Eq. (1) can be written in a more developed form

$$
\dot{m}_{c} \Delta h-\left.k_{t b} \pi d^{2} \frac{d T}{d r}\right|_{d / 2}+\varepsilon_{p} \pi d^{2} \sigma\left(T_{p}^{4}-T_{b}^{4}\right)=0
$$

Here, $T_{b}$ is the temperature of the bed in which the particle is embedded; $\varepsilon_{p}$ is the emissivity of a carbon particle, considered to be 0.85 [5],[6]; $\sigma$ is the constant of StefanBoltzeman; and $k_{t b}$ is the thermal conductivity of the bed surrounding the particle, which is considered the same as for air calculated at the film temperature between $T_{p}$ and $T_{b}$.

The conductive term of Eq. (2) should be expressed in its integral form, and for this purpose the equation of energy in spherical coordinates, Eq. (3), is used to obtain the radial temperature profile and its derivative at $d / 2$, which corresponds to the value of the radial coordinate at particle surface [7].

$$
\rho_{g} c_{p g} \nu_{r} \frac{d T}{d r}=k_{t b}\left[\frac{1}{r^{2}} \frac{d}{d r}\left(r^{2} \frac{d T}{d r}\right)\right]
$$

Being aware that $\dot{m}_{c}=\rho_{g} v_{r} 4 \pi r^{2}$, i.e. the net mass flow rate of gaseous matter that moves away from the particle is the same as the carbon consumption rate per particle, the energy equation takes the form

$$
\frac{d}{d r}\left(r^{2} \frac{d T}{d r}\right)=\frac{\dot{m}_{c} c_{p g}}{4 \pi k_{t b}} \frac{d T}{d r}
$$

defining $\beta=c_{p g} /\left(4 \pi_{k_{t b}}\right)$ and integrating with the boundary conditions

$$
\begin{array}{cc}
r=d / 2 & T=T_{p} \\
r \rightarrow \infty & T=T_{b}
\end{array}
$$

results for the radial temperature profile,

$$
T(r)=\frac{\left(T_{b}-T_{p}\right) \exp \left(-\frac{\beta \dot{m}_{c}}{r}\right)-T_{b} \exp \left(-\frac{\beta \dot{m}_{c}}{r}\right)+T_{p}}{1-\exp \left(-\frac{\beta \dot{m}_{c}}{r}\right)}(6)
$$

The derivative $d T /\left.d r\right|_{d / 2}$ can now be obtained and substituted in Eq. (2), leading to an equation for the calculation of the particle temperature $T_{p}$.

$$
\begin{aligned}
& \dot{m}_{c} \Delta h+\dot{m}_{c} c_{p g}\left(T_{p}-T_{b}\right) \frac{\exp \left(-\frac{\dot{m}_{c} c_{p g}}{2 \pi d k_{t b}}\right)}{\left[1-\exp \left(-\frac{\dot{m}_{c} c_{p g}}{2 \pi d k_{t b}}\right)\right]}+ \\
& +\varepsilon_{p} \pi d^{2} \sigma\left(T_{p}^{4}-T_{b}^{4}\right)=0
\end{aligned}
$$

In Eq.(7), the carbon conversion rate $\dot{m}_{c}$ and particle diameter $d$ are obtained from the experimental data.

\section{Experimental Procedure}

Single char particles made from Afzelia quanzensis and Pterocarpus angolensis were burned in a bubbling fluidized bed reactor operating at a fluidization velocity of $1.5 U_{m f}$ and at bed temperatures of 750,820 and 900 ${ }^{\circ} \mathrm{C}$. The reactor with $80.8 \mathrm{~mm}$ internal diameter was heated electrically, and the bed temperature was measured using a K-type thermocouple with $3 \mathrm{~mm}$ diameter and was controlled by a PID temperature controller. The inert material of the bed was silica sand in size range of 250-315 $\mu \mathrm{m}$, having a static height of 0.15 $\mathrm{m}$. The tested particles were approximately cubical and were machined from chars obtained through wood carbonization at $850{ }^{\circ} \mathrm{C}$ under a nitrogen atmosphere and for heating rates of $0.5{ }^{\circ} \mathrm{C} / \mathrm{s}$. The initial diameter $d_{p}$ of each particle, in the range $9-13 \mathrm{~mm}$, was calculated as the diameter of the sphere having the same volume as the particle times its sphericity [8]. The particles were measured with a vernier caliper to obtain their three basic linear dimensions.

The temperature inside the char particles was measured with a K-type thermocouple with an AISI 316 stainless steel sheath with $0.5 \mathrm{~mm}$ diameter. The acquisition and recording of bed and particles temperatures during the combustion experiment was done by means of the LabVIEW software and a NI USB-9211 data acquisition 


\section{Afzelia quanzensis}
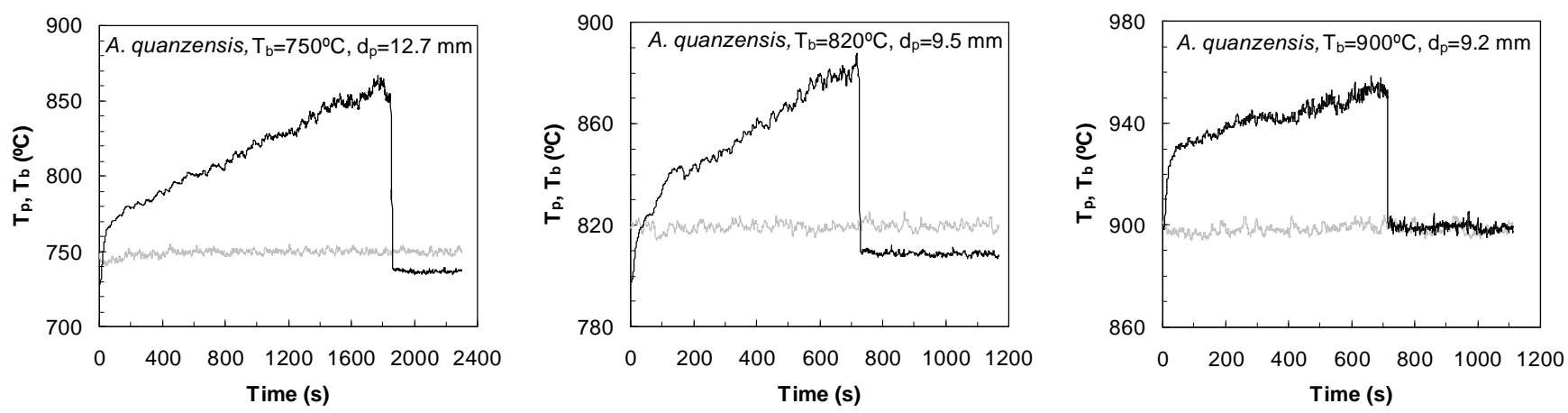

Pterocarpus angolensis
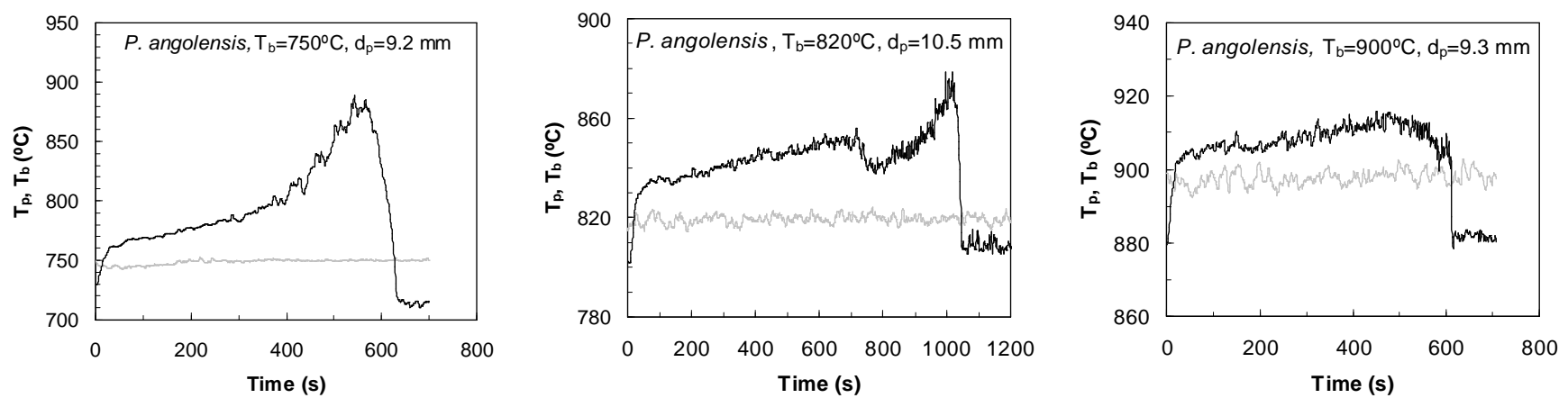

Fig. 2. Particle temperature $\left(-\mathrm{T}_{\mathrm{p}}\right)$ and bed temperature $\left(-\mathrm{T}_{\mathrm{b}}\right)$ along the combustion process. Data for wood chars of Afzelia quanzensis and Pterocarpus angolensis, at bed temperatures of $750-900{ }^{\circ} \mathrm{C}$. The sudden drop in particle temperature at the instant of the thermocouple detachment is very clear.

module with 24-bit resolution, both from National Instruments.

The char conversion rate and instantaneous particle diameter used in Eq. (7), for calculating the particle temperature, were obtained from a set of combustion tests with the same wood chars, but using batches of $1.5 \mathrm{~g}$ of particles with an average initial diameter of $3.6 \mathrm{~mm}$. The values of $\dot{m}_{c}$ and $d$ used here were for a burned mass fraction of $75 \%$. More details on these experiments can be found in Tomé [9].

\section{Results and Discussion}

Through the analysis of the evolution of the temperature inside the char burning particles it is clear that its value increases along the combustion process, or in other words, as the particle diameter diminishes its interior temperature raises, Fig. 2. It is then acceptable to say that when the particle reaches the completion of its combustion, the inserted thermocouple will now be closer to the particle surface and reading a temperature closer to the real superficial temperature of the particle, i.e. the temperature of the heterogeneous phase reaction zone. This occurs in the vicinity of the thermocouple detachment instant, see Fig. 2, and this value of peek temperature can be considered as the experimentally measured particle temperature [11].

At the end of the combustion process it might be expected that the $0.5 \mathrm{~mm}$ thick thermocouple reading would tend to the average bed temperature, but such does not happen in most cases as shown in Fig. 2. The reason for the observed discrepancy can be explained by the fact that the thermocouple used for bed temperature readings has a $3 \mathrm{~mm}$ diameter and thus it reads effectively an average between the flowing gas and the bed particles temperature [10], while the $0.5 \mathrm{~mm}$ diameter thermocouple will only, at the end of the particle combustion, read the flowing gas (air and combustion products) temperature, which is inferior to the average bed temperature. This difference can also be justified by the existence of temperature gradients inside the bubbling bed, which are easier detected by thinner thermocouples and are also dependent upon their position inside the bed.

The comparison of the experimental results with those obtained from the semi-analytical model of Eq. (7) is in Table I.

Table I. - Temperature differential between the bed and particle

\begin{tabular}{cccc}
\hline Wood char & $\mathrm{T}_{\text {bed }}\left({ }^{\circ} \mathrm{C}\right)$ & \multicolumn{2}{c}{ Temperature differential $\left({ }^{\circ} \mathrm{C}\right)$} \\
\cline { 3 - 4 } & & Calculated, Eq. $(7)$ & Measured \\
\hline A. quanzensis & 750 & 114 & 117 \\
& 820 & 90 & 68 \\
& 900 & 77 & 59 \\
\hline P. angolensis & 750 & 81 & 139 \\
& 820 & 68 & 59 \\
& 900 & 66 & 16 \\
\hline
\end{tabular}


In general, both the measured and calculated values of the temperature differential between the bed and particle are in agreement.

The discrepancies observed, particularly for the case of $P$. angolensis burning at $900{ }^{\circ} \mathrm{C}$, suggest that more experimental work should be done.

\section{Conclusion}

Experimental measurements of the interior temperature in cubical char particles made through carbonization of Afzelia quanzensis and Pterocarpus angolensis, burning in a laboratory scale bubbling fluidized bed, showed that their values increased along the combustion process. Calculated temperature values, obtained through an energy balance carried out at the surface of the burning particles, showed agreement with the measured data. Nevertheless, discrepancies were observed and justify further research work.

\section{Acknowledgement}

This work was financially supported in part by the grant SFRH/BPD/49250/2008 from Portuguese Foundation for Science and Technology. The tests were carried out in laboratory facilities of INEGI.

\section{Nomenclature}

$c_{p g} \quad$ Specific heat of the gas surrounding the particle

$$
\left(\mathrm{J} \mathrm{kg}^{-1} \mathrm{~K}^{-1}\right)
$$

d Particle diameter $(\mathrm{m})$

$d_{p} \quad$ Initial particle diameter $(\mathrm{m})$

$h_{c}$ Enthalpy of formation of carbon $\left(\mathrm{J} \mathrm{kg}^{-1}\right)$

$h_{\mathrm{co}}$ Enthalpy of formation of $\mathrm{CO}\left(\mathrm{J} \mathrm{kg}^{-1}\right)$

$h_{\mathrm{O} 2}$ Enthalpy of formation of $\mathrm{O}_{2}\left(\mathrm{~J} \mathrm{~kg}^{-1}\right)$

$k_{t b}$ Thermal conductivity of the bed surrounding the particle $\left(\mathrm{W} \mathrm{m}^{-1} \mathrm{~K}^{-1}\right)$

$\dot{m}_{c}$ Carbon conversion rate, per particle $\left(\mathrm{kg} \mathrm{s}^{-1}\right)$

$\dot{Q}_{s-i}$ Heat transfer rate to the interior of the char, per particle $\left(\mathrm{J} \mathrm{s}^{-1}\right)$

$\dot{Q}_{s-b}$ Heat transfer rate to the surrounding bed by conduction, per particle $\left(\mathrm{J} \mathrm{s}^{-1}\right)$

$\dot{Q}_{\text {rad }}$ Heat transfer rate to the surrounding bed by radiation, per particle $\left(\mathrm{J} \mathrm{s}^{-1}\right)$

$r \quad$ Radius of char particle; radial coordinate (m)

$T_{b} \quad$ Bed temperature $\left({ }^{\circ} \mathrm{C}, \mathrm{K}\right)$

$T_{p} \quad$ Particle temperature $\left({ }^{\circ} \mathrm{C}, \mathrm{K}\right)$
Greek symbols

$\beta$ Parameter, $c_{p g} /\left(4 \pi k_{t b}\right)$

$\Delta h$ Enthalpy of combustion for the reaction $\mathrm{C}+1 / 2 \mathrm{O}_{2} \rightarrow \mathrm{CO}\left(\mathrm{J} \mathrm{kg}^{-1}\right)$

$\varepsilon_{p} \quad$ Char emissivity

$\nu_{r} \quad$ Radial velocity $\left(\mathrm{m} \mathrm{s}^{-1}\right)$

$\rho_{g} \quad$ Gas density $\left(\mathrm{kg} \mathrm{m}^{-3}\right)$

$\sigma \quad$ Stefan-Boltzeman constant $\left(\mathrm{J} \mathrm{s}^{-1} \mathrm{~m}^{-2} \mathrm{~K}^{-4}\right)$

\section{References}

[1] J.C. Roscoe, A.R. Kwiatkowski, D. Harrison, "The Temperature of Coke Particles in Fluidised Combustor", Trans. Inst. Chem. Eng., 58 (1980), pp. 69-72.

[2] S.N. Oka, Fluidized Bed Combustion, Marcell Decker, lnc. (2004).

[3] Y.H. Khraisha, "Batch Combustion of Oil Shale Particles in Fluidized Bed Reactor", Fuel Process. Technol., 86 (2005), pp. 691-706.

[4] M. Komatina, V. Manovic, D. Dakic, "An Experimental Study of Temperature of Burning Coal Particle in Fluidized bed", Energy Fuels, 20 (2006), pp. 114-119.

[5] J. Adánez, L.F. de Diego, F. García-Labiano, A. Abad, J.C. Abanades, "Determination of Biomass Char Combustion Reactivities for FBC Applications by a Combined Method", Ind. Eng. Chem. Res., 40 (2001), pp. 4317-4323.

[6] G. Palchonok, C. Breitholtz, H. Thunman, B. Leckner, "Impact of Heat and Mass Transfer on Combustion of a Fuel Particle in CFB Boilers", in Proc. 14th Int. Conf. on FBC, Vancouver, BC, Canada, May 11-14, 1997, Vol. 2, pp. 871-878.

[7] S.R. Turns, An Introduction to Combustion: Concepts and Applications, McGraw-Hill International, New York (1996).

[8] C.K Gupta, D. Sathiyamoorthy, Fluid Bed Technology in Materials Processing, CRC Press (1999).

[9] N. Tomé, "Obtenção de Dados Cinéticos e Difusivos para a Queima de Biomassa de Origem Moçambicana", (Determination of Kinetic and Duffusive Data in the Combustion of Biomass of Mozambican Origin - In Portuguese). Integrated Master of Mechanical Engineering Dissertation, University of Porto (2011).

[10] J.S.M. Botteril, Fluid-Bed Heat Transfer, Academic Press, London (1975).

[11] F. Scala, "Fluidized-Bed Combustion of Single Coal Char Particles: An Analysis of the Burning Rate and of the Primary CO/CO 2 Ratio", Energy Fuels, 25 (2011), pp. 1051-1059. 